\title{
Metallo-Folded Single-Chain Nanoparticles with Catalytic Selectivity
}

\author{
Ana Sanchez-Sanchez, ${ }^{1,2}$ Arantxa Arbe, ${ }^{1}$ Juan Colmenero ${ }^{1,2,3}$ and José A. Pomposo ${ }^{* 1,2,4}$ \\ ${ }^{1}$ Centro de Física de Materiales (CSIC, UPV/EHU)-Materials Physics Center, Paseo Manuel de Lardizabal 5, 20018 San Sebastián, Spain \\ ${ }^{2}$ Departamento de Física de Materiales, Universidad del País Vasco (UPV/EHU), Apartado 1072, 20800 San Sebastián, Spain \\ ${ }^{3}$ Donostia International Physics Center (DIPC), Paseo Manuel de Lardizabal 4, 20018 San Sebastián, Spain \\ ${ }^{4}$ IKERBASQUE - Basque Foundation for Science, Alameda Urquijo 36, 48011 Bilbao, Spain
}

Supporting Information

\begin{abstract}
Mimicking the substrate specificity and catalytic activity of enzymes is of great interest for different fields (e.g., chemistry, biology, nanomedicine). Enhanced reaction rates using artificial, enzyme-mimic catalysts based on a variety of molecular structures and nano-entities (e.g., macrocyclic compounds, star and helical polymers, dendrimers) have been previously reported. However, examples of enzyme-sized soft entities displaying substrate specificity are certainly scarce. Herein, we report the synthesis and characterization of single-chain nanoparticles based on metallo-folded polymer chains containing complexed $\mathrm{Cu}(\mathrm{II})$ ions showing catalytic specificity during the oxidative coupling of mixtures of chemically related terminal acetylene substrates. This work paves the way for the easy and efficient construction of other $\mathrm{Pd}, \mathrm{Ni}, \mathrm{Co}, \mathrm{Fe}, \mathrm{Mn}$ or Mo-containing soft nano-entities approaching the substrate specificity of natural enzymes for a variety of organic reactions.
\end{abstract}

Enzymes showing outstanding catalytic activity and extreme substrate specificity are a continuing source of inspiration for green chemistry practitioners. Concerning catalytic activity, several artificial enzyme-mimic molecular structures and soft nanoentities approaching the size of natural enzymes have been synthesized based on macrocyclic compounds, ${ }^{1}$ star, $^{2}$ hyperbranched ${ }^{3}$ and helical ${ }^{4}$ polymers as well as dendrimers, ${ }^{5}$ among other systems. ${ }^{6}$ However, examples of soluble nano-sized soft catalysts displaying pronounced enzyme-like substrate specificity are relatively scarce. For instance, limited control over substrate specificity was achieved with 4-(dialkylamino) pyridine-functionalized polymers during the solvolysis of $p$-nitrophenyl alkanoates in aqueous methanol solution. ${ }^{7}$ Also, efficient hydrolysis of a phenyl ester compound was shown by a molecularly imprinted soluble polymer nanogel having a molecular weight of $40 \mathrm{kDa}{ }^{6 \mathrm{c}}$ To our best knowledge, no example of extraordinary catalytic specificity (i.e., reaction of only one substrate from a mixture of chemically related substances) has been reported by using synthetic soft nano-entities approaching the size of natural enzymes $(5-15 \mathrm{~nm})$.

The synthesis of biomimetic catalysts based on individual self-cross-linked polymer chains (single-chain nanoparticles, SCNPs) is challenging due to the polydisperse nature in size and composition of current synthetic polymers and the lack of efficient folding protocols. ${ }^{8,9}$ Consequently, current SCNPs mimic the structure of folded biomacromolecules only in an approximate manner. ${ }^{10}$ In spite of these limitations, SCNPs have been revealed as simple model systems to which valuable enzyme-like activity can be endowed by means of imprinted particle, ${ }^{6 c}$ hydrophobic cavity $^{11}$ or concurrent binding/folding ${ }^{12}$ strategies. In particular, the recently reported "concurrent" strategy opens new, promising avenues for endowing SCNPs with enzyme-mimetic properties such as outstanding catalytic activity and extreme substrate specificity.
Herein, we demonstrate how metallo-folded SCNPs containing complexed $\mathrm{Cu}$ (II) ions produced by means of such a versatile approach (Scheme 1, NP1) display catalytic specificity during the oxidative coupling of mixtures of chemically related terminal acetylene substrates. Such specificity is not affordable by classical catalysts (i.e., $\mathrm{CuCl}_{2}, \mathrm{Cu}(\mathrm{OAc})_{2}, \mathrm{Cu}(\mathrm{acac})_{2}$ ) under exactly the same reaction conditions. Moreover, a wide range of other metallo-folded SCNPs can be envisioned by appropriate selection of metal ions (e.g., $\mathrm{Pd}, \mathrm{Ni}, \mathrm{Co}, \mathrm{Fe}, \mathrm{Mn}, \mathrm{Mo}$ ) pointing to the potential broad scope of the concurrent binding/folding strategy.

We have prepared metallo-folded SCNPs based upon previously synthesized copolymers ${ }^{10}$ containing methyl methacrylate (MMA) and 2-(acetoacetoxy)ethyl methacrylate (AEMA) repeat units (Scheme 1, P1, see Supporting Information, SI) that feature $\beta$-ketoester reactive functions which serve as handles for concurrent binding/folding via intrachain $\mathrm{Cu}(\mathrm{II})$ complexation of AEMA units. SCNP formation was carried out under very mild conditions, in THF at room temperature by using $\mathrm{Cu}(\mathrm{OAc})_{2}$ as reagent at high dilution conditions $(1 \mathrm{mg} / \mathrm{ml})$ to minimize, as much as possible, unwanted inter-particle coupling events. We selected precursor P1 with a content of reactive AEMA units of $30 \mathrm{~mol} \%$, relatively high $M_{w}$ (weight average molecular weight, $M_{w}=375$ $\mathrm{kDa})$ and relatively low dispersity $(\fallingdotseq=1.4)$ to facilitate accurate detection of size reduction upon SCNP formation by combined size-exclusion chromatography / multi-angle laser light scattering (SEC / MALLS) measurements. The collapse of the linear copolymer precursor P1 to SCNP NP1 upon progressive addition of $\mathrm{Cu}(\mathrm{OAc})_{2}$ is illustrated in Figure 1A. A significant increase in retention time was observed for NP1 when compared to P1 as a consequence of the reduction in hydrodynamic size upon SCNP formation; an observation which is consistent with previous works in this field. ${ }^{13}$ The average radius of gyration was found to decrease from $26 \mathrm{~nm}$ for $\mathbf{P 1}$ to $15 \mathrm{~nm}$ for NP1, as determined by the MALLS technique. 
Scheme 1. Idealized picture of metallo-folded single-chain nanoparticle NP1 synthesized from precursor P1.

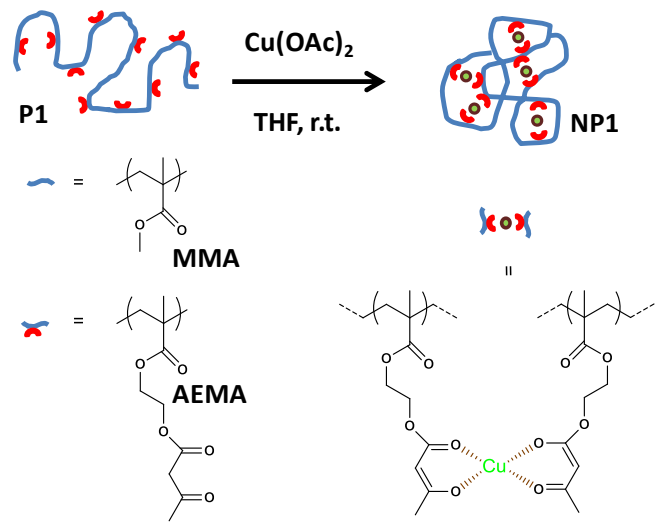

Evidence of AEMA complexation by copper ions was obtained by infra-red (IR) spectroscopy, in which characteristics vibration bands located at $1600 \mathrm{~cm}^{-1}$ (stretching $\mathrm{C}=\mathrm{O}$ vibration, enol tautomer bonded to $\mathrm{Cu}$ ) and $1515 \mathrm{~cm}^{-1}$ (stretching $\mathrm{C}=\mathrm{C}$ vibration, enol tautomer bonded to $\mathrm{Cu}$ ) were observed in the IR spectrum of NP1 (Figure 1B). In good solvent, NP1 shows a more compact conformation than that of precursor $\mathbf{P 1}$, as revealed by small angle neutron scattering (SANS) experiments (see Figures $1 \mathrm{C}$ and S1). The spherical shape of NP1 in the dry state is shown in Figure 1D. The copper incorporated into NP1 amounted to 26 mol \% with respect to AEMA units as deduced from thermal gravimetric analysis (TGA) (see Figure $\mathrm{S} 2$ ). The oxidation state of copper ions in the $\mathrm{Cu}(\mathrm{AEMA})_{2}$ complexes of NP1 was determined to be +2 by means of X-ray photoelectron spectroscopy (XPS) measurements (see Figure S3). The amount of metal incorporated into NP1 was similar to that in organometallic nanoparticles synthesized through intramolecular chelation of individual ROMP-derived poly(1,5-cyclooctadiene) chains by $\mathrm{Rh}(\mathrm{I})$ ions. ${ }^{14}$

Having shown a mild and efficient synthetic procedure to prepare metallo-folded SCNPs containing complexed $\mathrm{Cu}$ (II), we turned our attention towards the potential enzyme-mimic properties of these soft nano-entities when compared to classical catalysts (i.e., $\mathrm{CuCl}_{2}, \mathrm{Cu}(\mathrm{OAc})_{2}, \mathrm{Cu}(\mathrm{acac})_{2}$ ). Hence, to evaluate the catalytic activity and substrate specificity of copper-containing SCNPs, we explored their use as soft catalysts in an environmentally friendly, economical and efficient method ${ }^{15 a}$ for transforming terminal acetylenes into 1,3-diynes via oxidative coupling. It is worth mentioning that 1,3-diynes have attracted significant interest as building blocks for the construction of supramolecular materials, ${ }^{16} \pi$-conjugated acetylenic oligomers and polymers, ${ }^{17}$ industrial and pharmaceutical intermediates, ${ }^{18}$ as well as antitumor agents. ${ }^{19}$

Thus, as a first control experiment we performed the coupling of a series of terminal alkyne compounds to 1,3-diynes under optimized reaction conditions ${ }^{15 \mathrm{~b}}$ involving the use of catalytic amounts of $\mathrm{CuCl}_{2}(\mathbf{1})(3 \mathrm{~mol} \%)$ and $\mathrm{Et}_{3} \mathrm{~N}(3 \mathrm{~mol} \%)$. These acetylenic compounds were selected to cover a broad range of chemically related substrates (Scheme 2). The bulk homocoupling procedure gave the corresponding diynes in good to excellent yields (36 - 99\%, Table 1) with the exception of compound 8a having a bromo functional group (Table 1 , entry 8 ). As expected, catalyst 1 showed no specificity, since binary or ternary mixtures of terminal alkynes, as reagents, lead to complex mixtures of diynes, as products, due to both homo- and cross-coupling reactions (Table 1, entries 19, 21, 23, 25 and Figure 2). By reducing the amount of catalysts to $0.5 \mathrm{~mol} \% \mathrm{Cu}$ no reaction was observed to take place. The catalyst was found to work also in the presence of aromatic solvents (Table 1, entry 2).
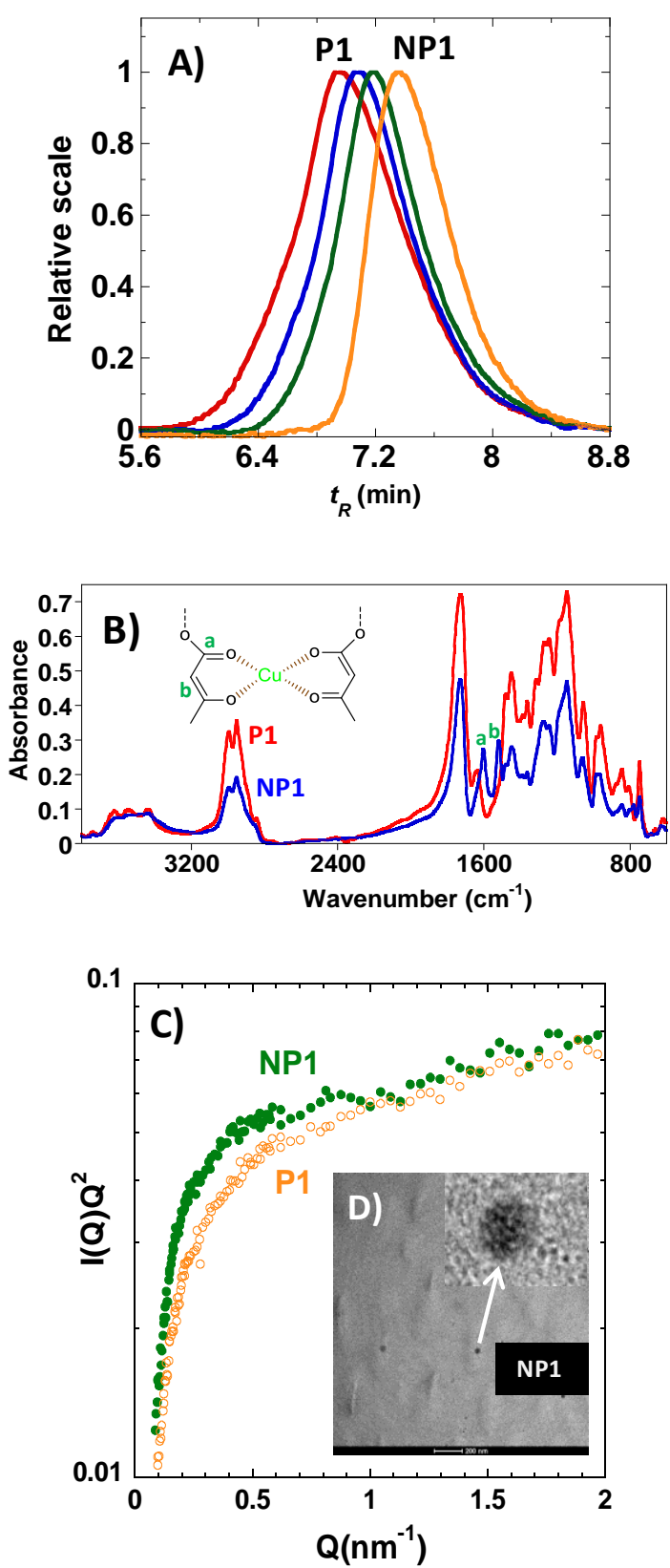

Figure 1. A) Size-exclusion chromatography traces in THF corresponding to the formation of NP1 by progressive addition of $\mathrm{Cu}(\mathrm{OAc})_{2}: 0.17 \mathrm{mM}$ (blue curve), $0.34 \mathrm{mM}$ (green curve) and $0.51 \mathrm{mM}$ (orange curve) to a $\mathbf{P 1}$ solution (red curve). B) IR spectra of precursor P1 and NP1 showing specific vibration bands $(\mathrm{a}, \mathrm{b})$ arising from $\mathrm{Cu}(\mathrm{AEMA})_{2}$ complexes. C) SANS Kratky plots of P1 and NP1 solutions. A shoulder is observed at low $\mathrm{Q}$ values due to a more compact conformation of NP1 in solution when compared to that of P1 (see SI). D) TEM image of NP1 in the dry state (inset is a magnification; NP1 size $\approx 20 \mathrm{~nm}$ ).

Interestingly, when we replaced the classical catalyst $\mathbf{1}$ by the metallo-folded SCNP NP1 at a lower concentration of $0.5 \mathrm{~mol} \%$ $\mathrm{Cu}$ we observed unprecedented catalytic specificity towards the propargylic substrate 2a ( $>98 \%$ yield, $\mathrm{R}_{1}=-\mathrm{CO}_{2} \mathrm{CH}_{3}$ ) and, to a minor extent, also towards the related compound $\mathbf{6 a}$ (27\% yield, $\mathrm{R}_{1}=-\mathrm{CO}_{2} \mathrm{CH}_{2} \mathrm{CH}_{3}$ ) (see Table 1 and Figure 2). Very good yield 


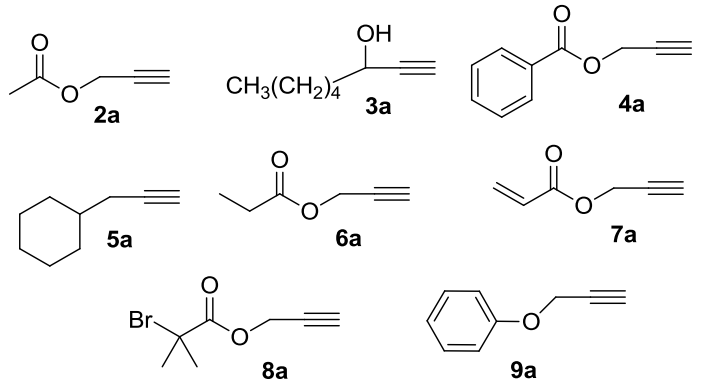

Table 1. Unprecedented catalytic selectivity of NP1 when compared to $\mathrm{CuCl}_{2}$ (1) during the coupling of terminal alkynes to 1,3-diynes under solvent-free conditions.

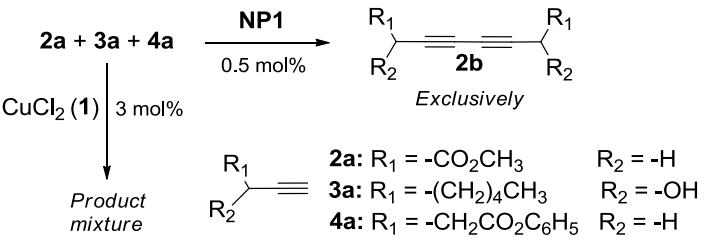

\begin{tabular}{|c|c|c|c|c|c|}
\hline Entry & Catalyst $^{\mathrm{a}}$ & Reagents & Products $^{\mathrm{b}}$ & Yield $(\%)^{\mathrm{b}}$ & Selectivity \\
\hline 1 & 1 & $2 a$ & $2 \mathbf{b}$ & $>98$ & - \\
\hline 2 & 1 & $2 a$ & $2 b$ & $93^{\mathrm{c}}$ & - \\
\hline 3 & 1 & $3 a$ & $3 b$ & $>98$ & - \\
\hline 4 & 1 & $4 a$ & $4 b$ & 57 & - \\
\hline 5 & 1 & $5 a$ & $5 \mathbf{b}$ & $>98$ & - \\
\hline 6 & 1 & $6 a$ & $6 b$ & $>98$ & - \\
\hline 7 & 1 & $7 a$ & $7 b$ & 36 & - \\
\hline 8 & 1 & $8 a$ & $8 \mathbf{b}$ & 0 & - \\
\hline 9 & 1 & 9a & $9 b$ & 77 & - \\
\hline 10 & NP1 & $2 a$ & $2 \mathbf{b}$ & $>98$ & - \\
\hline 11 & NP1 & $2 a$ & $2 b$ & $91^{\mathrm{c}}$ & - \\
\hline 12 & NP1 & $3 a$ & $3 \mathbf{b}$ & 0 & - \\
\hline 13 & NP1 & $4 a$ & $4 b$ & 0 & - \\
\hline 14 & NP1 & $5 a$ & $5 b$ & 0 & - \\
\hline 15 & NP1 & $6 a$ & $6 \mathbf{b}$ & 27 & - \\
\hline 16 & NP1 & $7 a$ & $7 b$ & 0 & - \\
\hline 17 & NP1 & $8 a$ & $8 \mathbf{b}$ & 0 & - \\
\hline 18 & NP1 & $9 a$ & $9 b$ & 0 & - \\
\hline 19 & 1 & $2 a+3 a$ & Mixture $^{\mathrm{d}}$ & 97 & No \\
\hline 20 & NP1 & $2 a+3 a$ & $2 \mathbf{b}^{\mathrm{e}}$ & $>98^{\mathrm{f}}$ & Yes \\
\hline 21 & 1 & $2 a+4 a$ & Mixture $^{\mathrm{d}}$ & 51 & No \\
\hline 22 & NP1 & $2 a+4 a$ & $2 \mathbf{b}^{\mathrm{e}}$ & $>98^{\mathrm{f}}$ & Yes \\
\hline 23 & 1 & $3 a+4 a$ & Mixture $^{\mathrm{d}}$ & 52 & No \\
\hline 24 & NP1 & $3 a+4 a$ & Mixture $^{\mathrm{g}}$ & 0 & Yes \\
\hline 25 & 1 & $2 a+3 a+4 a$ & Mixture $^{\mathrm{d}}$ & 84 & No \\
\hline 26 & NP1 & $2 a+3 a+4 a$ & $2 b^{e}$ & $>98^{\mathrm{f}}$ & Yes \\
\hline 27 & NP1 & $2 a+3 a+4 a$ & $2 \mathbf{b}^{\mathrm{e}}$ & $>98^{\mathrm{c}, \mathrm{f}}$ & Yes \\
\hline 28 & NP1 & $2 a+3 a+6 a$ & Mixture & $66^{\mathrm{h}}$ & Yes \\
\hline
\end{tabular}

${ }^{\mathrm{a}}$ Reaction conditions: solvent-free, $1 \mathrm{mmol}$ of alkyne, $\mathrm{Et}_{3} \mathrm{~N}$ ( $\left.3 \mathrm{~mol} \%\right), \mathbf{1}$ : $3 \mathrm{~mol} \% \mathrm{Cu}$, or NP1: $0.5 \mathrm{~mol} \% \mathrm{Cu}, 60{ }^{\circ} \mathrm{C}, 8 \mathrm{~h}$, air. ${ }^{\mathrm{b}}$ From GC and ${ }^{1} \mathrm{H}$ NMR data. ${ }^{c}$ Diluted with toluene to half of the original alkyne concentration. ${ }^{\mathrm{d}}$ Mixture of products as a result of combined homo- and crosscoupling reactions. ${ }^{\mathrm{e}}$ No by-products from cross-coupling reactions were detected. ${ }^{\mathrm{f}}$ Referred to $\mathbf{2 a} .{ }^{\mathrm{g}}$ Reaction time: 24 h. ${ }^{\mathrm{h}}$ Referred to $(\mathbf{2 a + 3 a + 6 a})$.
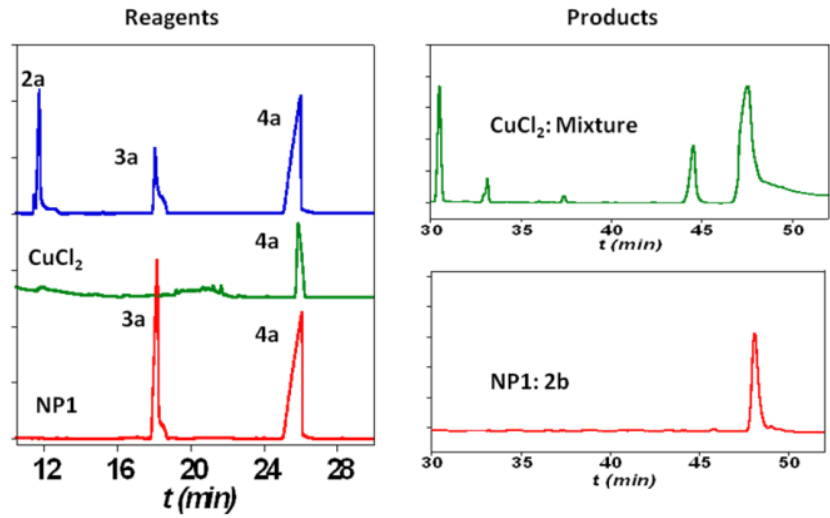

B)
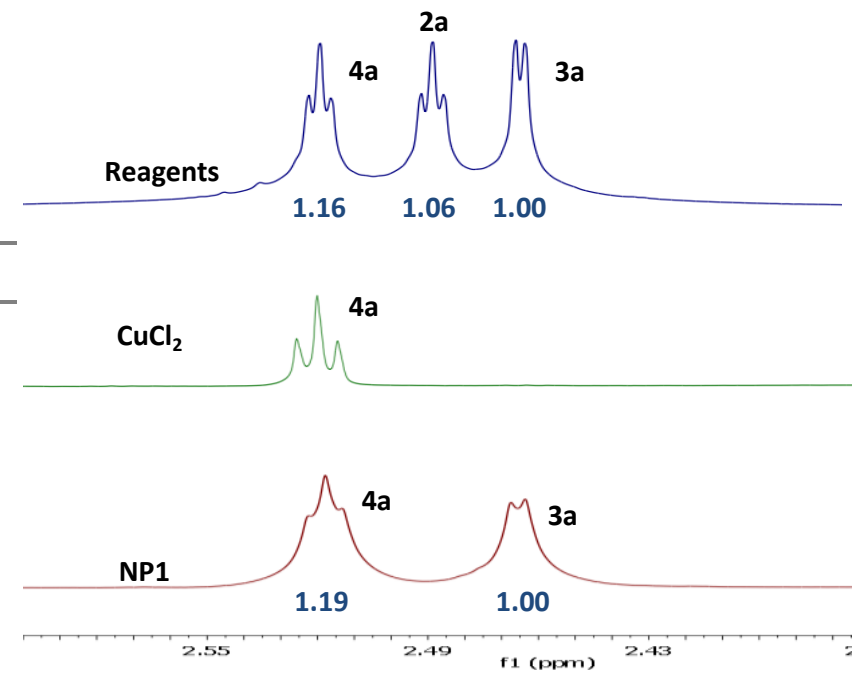

Figure 2. A) Gas chromatography (GC) traces of the $\mathbf{2 a}+\mathbf{3 a}+\mathbf{4 a}$ reagent mixture (blue trace) and products obtained by using $\mathrm{CuCl}_{2}$ (1) (green curve) or metallo-folded SCNPs NP1 (red curve) as catalysts during oxidative coupling. B) ${ }^{1} \mathrm{H}$ NMR spectra showing signals from acetylenic protons of the $\mathbf{2 a}+\mathbf{3 a}+\mathbf{4} \mathbf{a}$ reagent mixture (blue trace) and same spectral zone after reaction using $\mathrm{CuCl}_{2}$ (1) (green trace) or metallo-folded SCNPs NP1 (red trace) as catalysts during oxidative coupling. The peak area relative to that of peak $\mathbf{3 a}$ is indicated for the blue and red traces.

was also observed by running the reaction in aromatic solvent (Table 1, entry 11). Moreover, in competitive experiments involving ternary mixtures of $\mathbf{2 a}, \mathbf{3 a}$ and $\mathbf{4 a}$ (Table 1, entry 26) no sign of cross-coupling products was observed by GC, giving only $\mathbf{2 b}$ as the product in a highly selective manner. NP1 showed catalytic selectivity towards the propargylic substrates in mixtures of $\mathbf{2 a}, \mathbf{3 a}$ and $\mathbf{6 a}$ (Table 1, entry 28). Moreover, this selectivity towards 2a, and to a minor extension $\mathbf{6 a}$, was maintained in control experiments using compounds with a group more bulky than a proton near the acetate, or having an additional methylene group between the acetate group and the alkyne moiety (see SI). It is worth mentioning that neither $\mathrm{Cu}(\mathrm{OAc})_{2}$ nor $\mathrm{Cu}(\mathrm{acac})_{2}$ compounds were found to display significant catalytic activity at a concentration of $0.5 \mathrm{~mol} \% \mathrm{Cu}$ for compounds 2a-9a. Although this behavior could be tentatively attributed to a local environment in NP1 with a high enough amount of $\mathrm{Cu}$ complex concentration since the presence of a competitive solvent such as ethyl acetate slows the reaction, no reaction was observed in control experiments by increasing the $\mathrm{Cu}(\mathrm{acac})_{2}$ concentration even to $3 \mathrm{~mol} \% \mathrm{Cu}$ (see SI). At this stage, one can hypothesize that the pronounced substrate specificity 
displayed by NP1 when compared to $\mathrm{Cu}(\mathrm{OAc})_{2}$ and $\mathrm{Cu}(\mathrm{acac})_{2}$ complexes could result from the formation of multiple, compartmentalized local catalytic sites composed of $\mathrm{Cu}(\mathrm{AEMA})_{2}$ complexes surrounded by an environment of methyl methacrylate repeat units allowing an optimum transition state stabilization for the propargylic substrate $\mathbf{2 a}$ and, to a minor extent, $\mathbf{6 a}{ }^{6 \mathrm{~d}, 12}$

To further investigate the origin of the catalytic selectivity, the electronic absorption spectra of $\mathrm{Cu}(\mathrm{OAc})_{2}, \mathrm{Cu}(\mathrm{acac})_{2}$ and NP1 in dimethyl sulfoxide (DMSO) were recorded as illustrated in Figure 3. The UV-vis spectrum of the $\mathrm{Cu}(\mathrm{OAc})_{2}$ complex showed

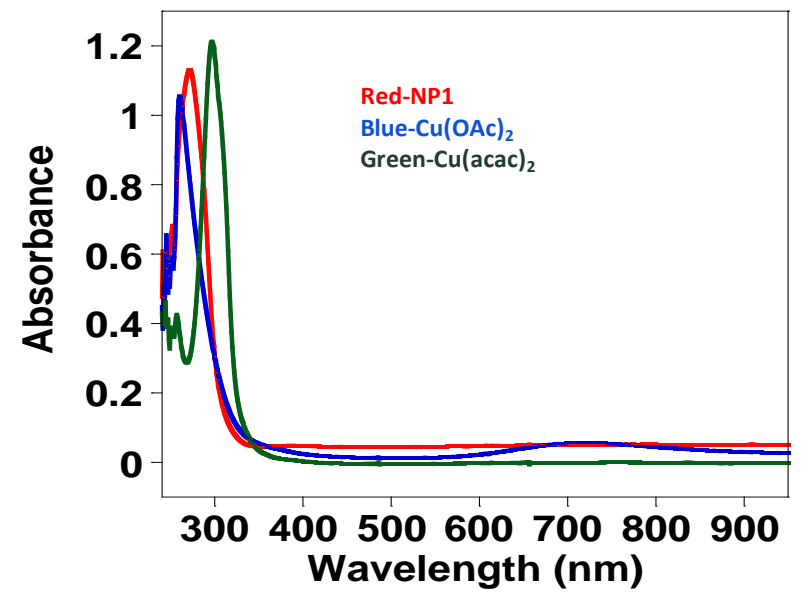

Figure 3. UV-vis spectra of $\mathrm{Cu}(\mathrm{OAc})_{2}, \mathrm{Cu}(\mathrm{acac})_{2}$ and $\mathrm{NP1}$ in DMSO.

one very broad $d-d$ band at $720 \mathrm{~nm}$ and a band in the UV region centered at $260 \mathrm{~nm}$ due to $\mathrm{Cu}$-to-OAc metal to ligand charge transfer (MLCT) transitions. ${ }^{20}$ The $\mathrm{Cu}(\mathrm{acac})_{2}$ complex displayed only a MLCT band at $297 \mathrm{~nm}$, whereas the NP1 showed a MLCT band centered at $271 \mathrm{~nm}$, a value in between those observed for the $\mathrm{Cu}(\mathrm{OAc})_{2}$ and $\mathrm{Cu}(\mathrm{acac})_{2}$ complexes. Both steric and electronic complementarities of the catalytic sites for $\mathbf{2 a}$ and to minor extent $\mathbf{6 a}$ in the rate-determining transition step could be responsible for the catalytic selectivity displayed by NP1. Analysis of kinetics data using $\mathbf{2 a}$ as reagent (see SI) provided a value of the apparent catalytic constant of $\mathrm{k}_{\text {cat }}($ app $)=8.8 \times 10^{-3} \mathrm{~s}^{-1}$, which is higher than that determined for molecularly imprinted soluble polymer nanogels $\left(\mathrm{k}_{\mathrm{cat}}=1.2 \times 10^{-6} \mathrm{~s}^{-1}\right)^{6 \mathrm{c}}$ and similar to that reported very recently for hydrophobic cavity-based catalytic SCNPs $\left(\mathrm{k}_{\mathrm{cat}}=5.3 \times 10^{-2}\right.$ $\left.\mathrm{s}^{-1}\right)$. ${ }^{11 \mathrm{a}}$

In summary, we have synthesized catalytically active singlechain nanoparticles based on metallo-folded polymer chains containing complexed $\mathrm{Cu}$ (II) ions by means of a mild and versatile concurrent binding/folding strategy. These synthetic soft nano-entities approaching the size of natural enzymes display catalytic specificity at low concentration of $\mathrm{Cu}$ (II) ions during the oxidative coupling of mixtures of chemically related terminal acetylene substrates, which cannot be attained with classical catalysts such as $\mathrm{CuCl}_{2}, \mathrm{Cu}(\mathrm{OAc})_{2}$ or $\mathrm{Cu}(\mathrm{acac})_{2}$. Such substrate specificity has been tentatively attributed to the presence in the metallo-folded nanoparticles of multiple, compartmentalized local catalytic sites composed of $\mathrm{Cu}(\mathrm{AEMA})_{2}$ complexes surrounded by an environment of methyl methacrylate repeat units allowing an optimum transition state stabilization for the preferred substrates. The specificity displayed by the metallo-folded SCNPs is very promising, and the preparation of other metallo-folded soft nanoobjects (based on $\mathrm{Pd}, \mathrm{Ni}, \mathrm{Co}, \mathrm{Fe}, \mathrm{Mn}$ and $\mathrm{Mo}$ instead of $\mathrm{Cu}$ ), as well as the study of their enzyme-mimic characteristics is anticipated.

\section{ASSOCIATED CONTENT}

\section{Supporting Information}

Materials and methods, characterization techniques, supporting data and references. This material is available free of charge via the Internet at http://pubs.acs.org.

\section{AUTHOR INFORMATION}

\section{Corresponding Author \\ Josetxo.pomposo@ehu.es Notes}

The authors declare no competing financial interests.

\section{ACKNOWLEDGMENT}

Financial support from the Projects MAT2012-31088 (MINECO), T-654-13 (GV) and S-PE13UN034 (GV) is acknowledged. A. S.S. thanks the Ph.D. grant support of Basque Government. We sincerely acknowledge David Pickup, Mariano Barrado, Lourdes Irusta, Urs Gasser and Lourdes Leza for technical support with XPS, TEM, GC, SANS and purification techniques, respectively. This work is based on experiments performed at the Swiss spallation neutron source SINQ, Paul Scherrer Institute, Villigen, Switzerland, and has been supported by the European Commission under the $7^{\text {th }}$ Framework Programme through the "Research Infrastructures" action of the "Capacities" Programme, NMI3-II Grant Number 283883.

\section{REFERENCES}

(1) a) Marinescu, L.; Bols, M. Curr. Org. Chem. 2010, 14, 1380. b) Bellia, F.; La Mendola, D.; Pedone, C.; Rizzarelli, E.; Saviano, M.; Vecchio, G. Chem. Soc. Rev. 2009, 38, 2756-2781. c) D’Souza, V. T. Supramol. Chem. 2003, 15, 221-229. d) Breslow, R.; Dong, S. D. Chem. Rev. 1998, 98, 1997-2012.

(2) a) Rodionov, V.; Gao, H.; Scroggins, S.; Unruh, D. A.; Avestro, A.-J.; Frechet, J. M. J. J. Am. Chem. Soc. 2010, 132, 25702572. b) Terashima, T.; Ouchi, M.; Ando, T.; Sawamoto, M. J. Polym. Sci. Part A: Polym. Chem. 2010, 48, 373-379. c) Dichtel, W. R.; Baek, K.-Y.; Frechet, J. M. J.; Rietveld, I. B.; Vinogradov, S. A. J. Polym. Sci., Part A: Polym. Chem. 2006, 44, 4939-4951. d) Helms, B.; Guillaudeu, S. J.; Xie, Y.; McMurdo, M.; Hawker, C. J.; Frechet, J. M. J. Angew. Chem. Int. Ed. 2005, 44, 6384-6387.

(3) a) Kirkorian, K.; Ellis, A.; Twyman, L. J. Chem. Soc. Rev. 2012, 41, 6138-6159. b) Van de Vyver, S.; Thomas, J.; Geboers, J.; Keyzer, S.; Smet, M.; Dehaen, W.; Jacobs, P. A. ; Sels, B. F. Energy Environ. Sci. 2011, 4, 3601-3610. c) PastorPerez, L.; Kemmer-Jonas, U.; Wurm, F.; Stiriba, S.-E.; PerezPrieto, J.; Frey, H. Macromolecules 2010, 43, 9583-9587.

(4) a) Zhang, D.; Ren, C.; Yang, W.; Deng, J. Macromol. Rapid Commun. 2012, 33, 652-657. b) Yamamoto, T.; Yamada, T.; Nagata, Y.; Suginome, M. J. Am. Chem. Soc. 2010, 132, 7899790. c) Terada, K.; Masuda, T.; Sanda, F. J. Polym. Sci. Part A: Polym. Chem. 2009, 47, 4971-4981. d) Maeda, K.; Tanaka, K.; Morino, K.; Yashima, E.Macromolecules 2007, 40, 6783-6785.

(5) a) Caminade, A. M.; Ouali, A.; Keller, M.; Majoral, J. P. Chem. Soc. Rev. 2012, 41, 4113-4125. b) Helms, B.; Frechet, J. M. J. Adv. Synth. Catal. 2006, 348, 1125-1148. c) Bosman, A. W.; Janssen, H. M.; Meijer, E. W. Chem. Rev. 1999, 99, 1665-1688.

(6) a) Lerner, R. A.; Benkovic, S. J.; Schultz, P. G. Science 1991, 252, 659-667. b) Schultz, P. G.; Lerner, R. A. Science 1995, 
269, 1835-1842. c) Wulff, G.; Chong, B.-O.; Kolb, U. Angew. Chem. Int. Ed. 2006, 45, 2955-2958. d) Wulff, G.; Chong, B.O. Acc. Chem. Res. 2012, 45, 239-247. e) Wei, H.; Wang, E. Chem. Soc. Rev. 2013, 42, 6060-6093.

(7) a) Wang, G.-J.; Fife, W. K. Macromolecules 1999, 32, 559564. b) Wang, G.-J.; Fife, W. K. J. Am. Chem. Soc. 1998, 120, 883-887.

(8) Altintas, O.; Barner-Kowollik, C. Macromol. Rapid Commun. 2012, 33, 958-971.

(9) Sanchez-Sanchez, A.; Perez-Baena, I.; Pomposo, J. A. Molecules 2013, 18, 3339-3355.

(10) Sanchez-Sanchez, A.; Akbari, S.; Etxeberria, A.; Arbe, A.; Gasser, U.; Moreno, A. J.; Colmenero, J.; Pomposo, J. A. ACS Macro Lett. 2013, 2, 491-495.

(11) a) Huerta, E.; Stals, P. J. M.; Meijer, E. W.; Palmans, A. R. A. Angew. Chem. Int. Ed. 2013, 52, 2906-2910. b) Terashima, T.; Mes, T.; De Greef, T. F. A.; Gillissen, M. A. J.; Besenius, P.; Palmans, A. R. A.; Meijer, E. W. J. Am. Chem. Soc. 2011, 133, 4742-4745.

(12) Perez-Baena, I.; Barroso-Bujans, F.; Gasser, U.; Arbe, A.; Moreno, A. J.; Colmenero, J.; Pomposo, J. A. ACS Macro Lett. 2013, 2, 775-779.

(13) a) Sanchez-Sanchez, A.; Fulton, D. A.; Pomposo, J. A. Chem. Comm. 2014, 50, 1871-1874. b) Whitaker, D. E.; Mahon, C. S.; Fulton, D. A. Angew. Chem. Int. Ed. 2013, 52, 956-959. c) Tuten, B. T.; Chao, D.; Lyon, C. K.; Berda, E. B. Polym. Chem. 2012, 3, 3068-3071. d) Pomposo, J. A.; Perez-Baena, I.; Buruaga, L.; Alegria, A.; Moreno, A. J.; Colmenero, J. Macromolecules 2011, 44, 8644-8649. e) Harth, E.; Horn, B. V.; Lee, V. Y.;
Germack, D. S.; Gonzales, C. P.; Miller, R. D.; Hawker, C. J. J. Am. Chem. Soc. 2002, 124, 8653-8660.

(14) Mavila, S.; Diesendruck, C. E.; Linde, S.; Amir, L.; Shikler, R.; Lemcoff, N. G. Angew. Chem. Int. Ed. 2013, 52, 5767-5770.

(15) a) Wang, D.; Li, J.; Li, N.; Gao, T.; Hou, S.; Chen, B. Green Chem. 2010, 12, 45-48. b) Although $6 \mathrm{~h}$ of reaction time was reported as optimum reaction time, we found increased yields by extending the reaction time to $8 \mathrm{~h}$.

(16) a) Mukai, M.; Kogiso, M.; Aoyagi, M.; Asakawa, M.; Shimizu, T.; Minamikawa, H. Polym. J. 2012, 44, 646-650. b) Jahnke, E.; Millerioux, A.-S.; Severin, N.; Rabe, J. P.; Frauenrath, H. Macromol. Biosci. 2007, 7, 136-143. c) Lindsell, W. E.; Preston, P. N.; Seddon, J. M.; Rosair, G. M.; Woodman, T. A. J. Chem. Mater. 2000, 12, 1572-1576.

(17) a) Jahnke, E.; Lieberwirth, I.; Severin, N.; Rabe, J. P. Frauenrath, H. Angew. Chem. Int. Ed. 2006, 45, 5383-5386. b) Martin, R. E.; Diederich, F. Angew. Chem. Int. Ed. 1999, 38, 13501377.

(18) a) Shun, A. L. K. S.; Tykwinski, R. R. Angew. Chem. Int. Ed. 2006, 45, 1034-1057. b) Shun, A. L. K. S.; Tykwinski, R. R. J. Org. Chem. 2003, 68, 6810-6813. c) DeCicco, R. C.; Black, A.; Li, L.; Goroff, N. S Eur. J. Org. Chem. 2012, 25, 4699-4704. d) Eastmond, R.; Johnson, T. R.; Walton, D. R. M. Tetrahedron 1972, 28, 4601-4616.

(19) a) Jin, H. R.; Zhao, J.; Zhang, Z.; Liao, Y.; Wang, C. Z.; Huang, W. H.; Li, S. P.; He, T. C.; Yuan, C. S.; Du, W. Cell Death Dis. 2012, 3, e376. b) Dembitsky, V. M. Lipids 2006, 41, 883924. c) Setzer, W. N.; Gu, X.; Wells, E. B.; Setzer, M. C.; Moriarity, D. M. Chem. Pharm. Bull. 2000, 48, 1776-1777.

(20) Lever, A. B. P. Inorganic Electronic Spectroscopy, $2^{\text {nd }}$ Ed.; Elsevier: Amsterdam, 1984; pp 553-572 and 636-638. 
Insert Table of Contents artwork here

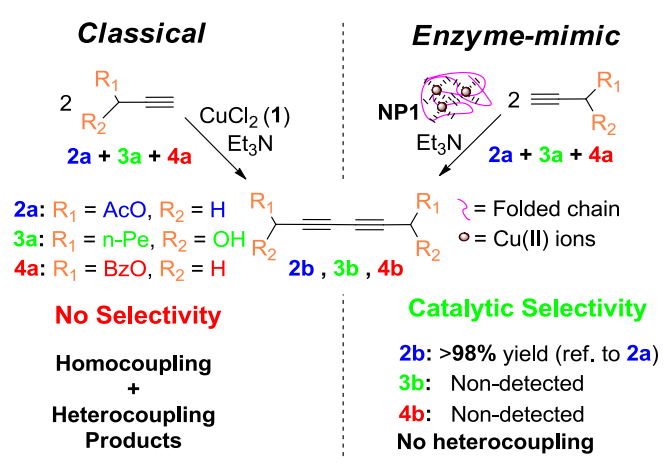

